\title{
Adequacy of Technical Facilities for Maternal Health Care Delivery in Public Secondary and Tertiary Facilities in Osun State, Nigeria
}

\author{
Asa, Soladoye S. ${ }^{1 a}$; Fatusi, A.O. ${ }^{\text {; }}$ Ilori, M.O. ${ }^{c}$ and Osagbemi, Kayode ${ }^{d}$ \\ ${ }^{a}$ Department of Demography and Social Statistics, Obafemi Awolowo University, lle-Ife, Nigeria \\ ${ }^{b}$ Department of Community Medicine, Obafemi Awolowo University, Ile-Ife, Nigeria \\ ${ }^{c}$ African Institute for Science Policy and Innovation, Obafemi Awolowo University, Ile-Ife, Nigeria \\ ${ }^{\mathrm{d}}$ Department of Community Medicine, University of Ilorin, Ilorin, Nigeria
}

\begin{abstract}
Nigeria has one of the highest maternal mortalities and morbidities in the world, and the need to address these challenges continues to engage the attention of relevant stakeholders but very little attention has focused on technological resources within the maternal health research agenda. This study aims to identify and determine the adequacy of the key equipment for emergency obstetric care (EmOC) services in public-sector secondary and tertiary health facilities in Osun State, Southwest, Nigeria. Using a two-stage probability sampling procedure, 7 health facilities based in 6 randomly selected Local government areas (LGAs) were involved in the study. Data were obtained through the use of primary and secondary sources. For primary sources, a questionnaire was administered to II 2 health workers and the study also utilized a checklist for equipment inventory. For secondary sources we reviewed existing hospital records on technology acquisition and maintenance. Relevant descriptive and inferential statistics were used for the data analysis. Almost three-fifths (58.1\%) of the health workers considered the technical facilities for the delivery of EmOC in their facilities as inadequate, the proportion of health workers with such opinion was significantly higher in secondary compare to tertiary facilities $(60.0 \%$ vs $40.0 \%, p=0.003)$. The inventory review and use of the checklist also showed varying degree of inadequate technical facilities; none of the facilities had all the 26 equipment considered as essential for comprehensive EmOC in functional state. We concluded that the public sector facilities in Osun State have inadequate technical facilities for EmOC; addressing this technological challenge will be critical to improving maternal health outcomes and statistics in Nigeria.
\end{abstract}

Keywords Emergency Obstetric Care, Secondary Healthcare Facilities, Tertiary Healthcare Facilities, Technology Acquisition, Technical Facilities

\section{Résumé}

Le Nigeria a l'un des taux de mortalité et de morbidité maternelle les plus élevés au monde. Même si les parties intéressées sont attentives au besoin de palier à ce fléau, peu d'attention a été dévolue au ressources techniques dans les études et recherches concernant la sante maternelle. Cette étude essaie d'identifier et de déterminer l'adéquation des équipements-clés de soins obstétriques d'urgence (EmOC) dans le secteur public secondaire et tertiaire des établissements de santé dans l'Etat d'Osun, au Sud-Ouest du Nigeria. Utilisant un échantillonnage de probabilité à deux temps, 7 établissements de santé se situant dans 6 zones de gouvernance locale (LGAs) choisis au hasard ont fait l'objet de cette étude. Les données ont été obtenues grâce à un formulaire rempli par 112 professionnels de santé et un inventaire des équipements disponibles, en plus de sources secondaires (un examen des fichiers des hôpitaux sur l'acquisition et la maintenance des équipements). Des statistiques descriptives et différentielles sont utilisées pour analyser les données. Presque les $3 / 5(58,1 \%)$ des professionnels de la sante considèrent que les infrastructures techniques d'offre de soins obstétriques d'urgence (EmOC) sont inadéquats. La proportion des professionnels qui sont de cette opinion est beaucoup plus élevée

\footnotetext{
${ }^{1}$ Correspondencing Author: Asa Soladoye Sunday

Department of Demography and Social Statistics, Obafemi Awolowo University, lle-Ife, Nigeria

+2348037220624

solaasa2000@yahoo.com

sasa@oauife.edu.ng
} 
pour les structures secondaires que tertiaires $(60,0 \%$ contre $40,0 \%, p=0,003)$. La revue de l'inventaire et l'étude des listes d'équipements disponibles aussi montre à des degrés divers l'inadéquation des plateaux techniques pour les soins obstétriques d'urgence; aucune des infrastructures n'a toutes les 26 machines considérées comme essentielles pour de tels soins dans un Etat qui fonctionne normalement. Nous concluons que les infrastructures publiques dans l'Etat d'Osun sont inadéquates pour la provision de soins obstétriques d'urgence. Palier à ces difficultés techniques est crucial pour améliorer la santé maternelle au Nigeria..

Mots-clés: Soins Obstétriques d'Urgence, Etablissements Sanitaires Secondaires, Etablissements Sanitaires Tertiaires, Acquisition Technique, Infrastructures Sanitaires

\section{Introduction}

The fifth Millennium Development Goal (MDG5) specifically focuses on maternal health and one of its key indicators is reduction in maternal mortality ratio by three quarters between 1990 and 2015. Nigeria is one of the countries with the highest burden of maternal deaths in the world. According to United Nation sources, Nigeria has a high maternal mortality ratio (MMR) of 630 per 100,000 live births (WHO, 2013). Whereas, Nigeria accounts for about $2 \%$ of the world population, it contributes over $10 \%$ of the global maternal death figure (Nove, 201I; WHO, 2013). Addressing the unacceptably high level of maternal mortality is a major national priority as reflected in critical national policy documents such as the National Policy on Health (FMOH, 2005), National Reproductive Health Policy (FMOH, 2010) and Nigeria Health Strategic Development Plan Framework (2009-20I5) (FMOH, 2009). As such the Nigerian government and its development partners have initiated a number of programmes aimed at reducing maternal mortality and improving maternal health particularly in the recent years, although some progress have been recorded, available statistics show that the country is not on track to meet the MDG5 target (WHO, 2013).

\section{Literature Review and Theoretical Framework}

In addition to maternal mortality, maternal morbidity is also a major challenge although it has not come under the same degree of global or national attention: for every maternal death, about 20-30 other women are estimated to suffer maternal morbidity including serious health challenges with life-long implications such as obstetric fistula (vesicovaginal or/and recto-vaginal fistula) (WHO, 2013). Nigeria is one of the countries with the highest burden of obstetric fistula in the world, and a priority country for interventions proposed or being implemented by various international agencies to address the condition (WHO, UNICEF AND UNFPA, 2010).
The provision of skilled care at delivery and access to emergency obstetric care are globally recognized as the most widespread approaches for addressing maternal mortality and morbidity. Skilled care in its true sense as the World Health Organisation (WHO) has aptly noted, is not just about the availability of individuals trained to proficiency in the handling of pregnancy- related events and associated complications, but there must also be the necessary equipment and medications to allow the healthcare professional to put his/her skills to the full advantage of the client (WHO, 2009). Zafarullah (2000) noted that properly functioning equipment is as important as staff readiness, physical facilities and supplies when providing essential obstetric care (EmOC) services. A health facility has technical facilities as an integral part of the physical infrastructure and hence the quality of health services is improved by the availability and utilization of medical equipment (Pardeshi, 2005). The study by the Prevention of Maternal Mortality (PMM) Network in Nigeria, for example, has showed that shortage or lack of essential supplies and equipment are major reasons for long-admission to treatment intervals (PMM, 1995). Thus, the acquisition and maintenance of technological resources are critical to providing quality maternal health services including effective EmOC services.

Some of the major problems, associated with low level of access to quality reproductive health information and services in Nigeria include "the poor quality of available basic infrastructure and logistic support owing to inadequate maintenance of buildings, medical equipment and vehicles, inadequate and unreliable supply of potable water and electricity and the poor management of drugs, vaccines and supplies system" (FMOH, 200I) In this respect, the 200I National Reproductive Health indicated that one of the intentions of the country in its bid to improve the availability, accessibility and quality of maternal health services and other components of reproductive health is: "to develop and encourage use of technologies and methodologies appropriate to effective delivery of quality reproductive health care at all levels" $(\mathrm{FMOH}$, 
200I). As such the government and other partners have continued to invest in infrastructural development in Nigerian health facilities, but very little is known about the adequacy and functionality of available technological resources for maternal health care. Broadly, research efforts regarding maternal health in Nigeria have focused more on clinical dimensions and care-seeking behaviour of clients, human resources (qualification, years of experience and technological capability) but less on the issues and contributions of technological resources for EmOC. Improvement in the maternal healthcare delivery could be further enhanced by the adequacy and functionality of technological resources. To this end a workable intervention policy based on a combination of all identified factors including provision of adequate and functional technical resources could be put in place. Adequacy of technological resources will be based on the population of pregnant women attending these health facilities.

\section{Data and Methods}

The study was conducted in Osun State located in Southwestern Nigeria in 2012, a State which is most populated by the Yoruba, has a total of two public sector tertiary health facilities and 54 secondary health facilities $(\mathrm{FMOH}, 20 \mathrm{II})$. The tertiary health facilities are teaching hospitals affiliated to the two medical schools in the state. One is owned by the Federal Government of Nigeria named Obafemi Awolowo University Teaching Hospitals Complex (OAUTHC) located in lle-lfe and the other by the state government named Ladoke Akintola University of Technology (LAUTECH) Teaching Hospital located in Osogbo.

Tertiary healthcare facilities provide all categories of health services and are at the apex of Nigeria's three-tier healthcare system. The Secondary healthcare facilities consisted of General Hospitals and Comprehensive Health Centres. The State enjoys the World Bank Assisted Health System Development Project (HSDP). The major focuses of the HSDP include strengthening of the capacity for systems management at the State Ministry of Health, strengthening of the delivery of priority health services and improvement in accessibility to health care. In order to realize the objectives of the HSDP, funds from the World Bank were used for civil works including the construction of new health facilities as well as the renovation of existing ones; improvement of the quality of health professions training schools (School of Nursing and Midwifery, and School of Health Technology); and procurement and distribution of goods and medical equipment among others (Osun State Ministry of Health, 2009).

Osun State has a total of 31 Local Government Areas (LGA), spread over three Senatorial districts. Each of the three Senatorial districts is made up of three Federal constituencies. A two-stage probability sampling was employed in selecting two LGAs from each of the three Senatorial districts making a total of six LGAs. For this purpose, two federal constituencies were first selected from each of the three senatorial districts by simple random sampling. Then one LGA was selected by simple random approach from each of the selected federal constituencies. The study covered all the secondary health care facilities in each of the selected LGAs as well as the two tertiary health care facilities in the state. The sample size consists of five (5) Secondary Healthcare Facilities as well as two (2) Tertiary Healthcare Facilities. This constitutes a total enumeration of all the Secondary and Tertiary Healthcare Facilities in the selected LGAs.

Data were obtained through primary and secondary sources in the health facilities. The primary sources included health care workers such as doctors, nurses and technologists attached to the reproductive units of the health facilities. In this regard, primary data were collected from all health workers located in the five major maternal units through the use of self-administered structured questionnaire. Other primary sources included one randomly selected member of State Health Management Team, a Consultant Gynecologist or a Biomedical Engineer in each of the health facilities. The secondary source included existing hospital records with particular reference to available technical facilities. A Chief Nursing Officer, an experienced staff nurse, a technologist or a biomedical engineer is identified to supply the information needed on the adequacy of technical facilities.

Three data collection tools were used in the study, namely the structured questionnaire, the key Informant guide and the health records observational checklists. The question used in the study were adopted from a number of existing standard instruments, including the study instrument for a national study on essential obstetric care facility in Nigeria (FMOH, 2003), and the National HIV/AIDS and Reproductive Health Survey (NARHS). The checklist took cognizance of the signal functions of EmOC, and identified equipment critical to the performing of each signal function was identified. The signal functions for comprehensive EmOC are: (i) administration of parental antibiotics; administration of uterotonic drugs (iii) administration of parenteral anticonvulsants for pre-eclampsia and 
eclampsia; (iv) manual removal of placenta; (v) removal of retained products; (vi) assisted vaginal delivery.(e.g. vacuum extraction, forceps delivery); (vii) basic neonatal resuscitation (e.g. with bag and mask); (viii) surgery (e.g. caesarean section); and (ix) blood transfusion. The list of equipment compiled, based on these signal functions, was presented to university-based experts in maternal health services for revision and finalization. All in all a total of twentysix medical equipment were included in the final checklist.

\section{Results}

A total of 112 respondents participated in the study of which $83.9 \%$ were females. Almost half (49.1\%) of the respondents were working with the federal government owned health institutions, while $50.9 \%$ of the respondents were with state government owned health institutions. The average age of respondents interviewed was $37( \pm 10)$ years. More than one-third $(4 \mathrm{I} .1 \%)$ of the respondents were at least 40 years old as at the time of the survey and $84.1 \%$ of the respondents were in the reproductive age group ( $15-49$ years).

Doctors constituted $15.2 \%$, while $47.3 \%$ were nurse/midwives and $36.6 \%$ single-qualified nurses. Less than a quarter of the respondents $(23.2 \%)$ were working in antenatal clinic, while $38.4 \%$ were working in labour ward units. The working years of respondents as trained reproductive health personnel ranged between 10 and 33 years with seven years as median year of working experience. Overall 39.3\% of the respondents had spent at least 10 years as trained reproductive health personnel in all the different five maternal health care units of the health facilities (antenatal clinic, antenatal ward, labour ward, and post-natal ward, post-natal ward, and Obstetrics and Gynecology Theater).

Table I Distribution of respondents by some socio-demographic characteristics

\begin{tabular}{|c|c|c|}
\hline Work status & $\begin{array}{l}\text { Frequency } \\
(n=|I| 2)\end{array}$ & Percentage \\
\hline \multicolumn{3}{|l|}{ Age (years) } \\
\hline$<25$ & 14 & 13.1 \\
\hline $25-29$ & 18 & 16.8 \\
\hline $30-34$ & 16 & 15.0 \\
\hline $36-39$ & 15 & 14.0 \\
\hline$>39$ & 44 & 41.1 \\
\hline \multicolumn{3}{|l|}{ Gender } \\
\hline Male & 18 & 16.1 \\
\hline Female & 94 & 83.9 \\
\hline \multicolumn{3}{|l|}{ Nature of work } \\
\hline Nurse & 53 & 47.3 \\
\hline Midwife & 41 & 36.6 \\
\hline Doctor & 17 & 15.2 \\
\hline Technologist & I & 0.9 \\
\hline \multicolumn{3}{|l|}{ Present unit of work } \\
\hline Antenatal clinic & 26 & 23.2 \\
\hline Antenatal ward & 13 & 11.6 \\
\hline Labour ward & 43 & 38.4 \\
\hline Gynea theatre & 15 & 13.4 \\
\hline Postnatal ward & 15 & 13.4 \\
\hline \multicolumn{3}{|c|}{ Length of years working as trained reproductive health worker } \\
\hline$<1$ & 5 & 4.5 \\
\hline $1-9$ & 63 & 56.3 \\
\hline $10-19$ & 24 & 21.5 \\
\hline $20-29$ & 14 & 12.5 \\
\hline$>29$ & 76 & 5.4 \\
\hline \multicolumn{3}{|c|}{ Ownership of Health Facility } \\
\hline Federal Government & 55 & 49.1 \\
\hline State Government & 57 & 50.9 \\
\hline
\end{tabular}


Table 2 Respondents' rating of maternal health events and services

\begin{tabular}{llll}
\hline \multicolumn{1}{c}{ Maternal health situation } & \multicolumn{3}{c}{ Rating } \\
\cline { 2 - 4 } & \multicolumn{1}{c}{ High } & Average & Low \\
\hline Level of maternal complications & $9(8.2)$ & $21(19.1)$ & $80(72.7)$ \\
Level of maternal deaths & $6(5.5)$ & $6(5.5)$ & $97(89.0)$ \\
Level of management of maternal morbidity & $52(47.3)$ & $32(29.1)$ & $26(23.2)$ \\
Level of management of maternal complications & $56(50.9)$ & $29(26.4)$ & $25(22.7)$ \\
Level of technical skills in the management of maternal morbidity & $67(61.5)$ & $35(32.1)$ & $7(6.4)$ \\
Level of technical skills for the management of maternal complications & $64(58.7)$ & $35(33.9)$ & $8(7.3)$ \\
\hline
\end{tabular}

\section{Respondents' rating of maternal events and services} As Table 2 shows, $72.7 \%$ of respondents rated the level of maternal complications in their facilities as low and, $89.0 \%$ rated the level of maternal deaths as low. However, only about half of the respondents (50.9\%) opined that their facility has high quality level of management for maternal complications. The proportion of respondents that rated the quality of technical skills as high was $58.7 \%$ for maternal complications and $61.5 \%$ for maternal morbidities.

\section{Respondents' opinion about technical facilities}

Most respondents $(58.1 \%)$ rated the technical facilities available for maternal health in their facilities as inadequate (Table 3). However, compared to $68.4 \%$ of the respondents in secondary facilities who indicated that their facilities were inadequate in technical terms, a significantly lower proportion $(47 \%)$ of the respondents in tertiary facility were of similar opinion $(p=0.003)$. As Table 3 further shows, $61.5 \%$ of the respondents indicated that technical skills in the management of maternal morbidity was high while $58.3 \%$ also indicated that the technical skills for managing maternal complications was high: there was no statistically significant difference between respondents in secondary and tertiary facilities in these regard.

Table 3 Respondents' opinion about technical facilities in their health facilities

\begin{tabular}{lccc}
\hline \multirow{2}{*}{ Respondents' opinion } & \multicolumn{2}{c}{ Level of health facilities } & \multirow{2}{*}{ p-value } \\
\cline { 2 - 3 } & $\begin{array}{c}\text { Tertiary } \\
(\mathrm{N}=55)\end{array}$ & $\begin{array}{c}\text { Secondary } \\
(\mathrm{N}=57)\end{array}$ & \\
\hline Adequacy of technical facilities & $26(47.3)$ & $39(68.4)$ & \\
Not adequate & $26(47.3)$ & $10(17.5)$ & \\
About adequate & $3(5.4)$ & $8(14.1)$ & $0.003^{*}$ \\
Adequate & & & \\
Technical skill in managing maternal morbidity & $27(50.9)$ & $40(71.4)$ & \\
High & $22(41.5)$ & $13(23.2)$ & \\
Average & $4(7.6)$ & $3(5.4)$ & 0.086 \\
Low & & & \\
Technical skill in managing maternal complication & $28(52.8)$ & $36(64.3)$ & \\
High & $21(39.6)$ & $16(28.6)$ & \\
Average & $4(7.6)$ & $4(7.1)$ & $0.45 \mid$ \\
Low & & & \\
\hline
\end{tabular}

* Significant at 0.05 level of significance 


\section{Inventory of available technical facilities}

Table 4 shows the findings with regards to availability of the desired equipment for EmOC services based on the use of checklists. None of the facilities assessed had all the 26 equipment for Comprehensive EmOC services listed in the checklist.

Table 4 Adequacy of technical facilities by level of facility based on the use of checklist

Level of facilities

Technical facilities

\begin{tabular}{llllllllll}
\hline \multicolumn{3}{c}{ Tertiary } & \multicolumn{4}{c}{ Secondary } & & All & \\
& & & & & & & & \\
\hline NR & NoG & NF & NR & NoG & NF & NR & NoG & NF
\end{tabular}

\begin{tabular}{|c|c|c|c|c|c|c|c|c|c|}
\hline Laparoscopy set & 2 & $\mathrm{I}$ & 0 & 4 & & & I & $\mathrm{I}$ & $\mathrm{I}$ \\
\hline Ultrasound Machine & & 1 & I & 4 & I & 0 & 4 & I & I \\
\hline Cardiotocograph Machine & & & & 2 & 0 & 0 & 2 & 0 & 0 \\
\hline Sonicaide & & & & 2 & 0 & 0 & 2 & 0 & 0 \\
\hline Resuschitaire for baby & 1 & I & 1 & 4 & I & I & 3 & I & I \\
\hline Incubator for baby & 40 & 32 & 20 & 5 & I & 1 & 12 & 8 & 6 \\
\hline Hysteroscope & & & & 4 & 0 & 0 & 4 & 0 & 0 \\
\hline Angle-poised lamp & 5 & 2 & 2 & 6 & 2 & 2 & 6 & 2 & 2 \\
\hline Gynaecological couch & & & & 7 & 3 & 3 & 7 & 3 & 3 \\
\hline Gynaecological Operating table/lamp & 3 & 3 & 3 & 5 & 2 & 1 & 5 & 2 & 2 \\
\hline Vacuum Extractor with metal cups & & & & 4 & I & 1 & 4 & I & I \\
\hline Ambubag for adult & 2 & 1 & 1 & 6 & 2 & 2 & 5 & 2 & 2 \\
\hline Ambubag for Paediatrics & 2 & 1 & 1 & 6 & I & 1 & 5 & I & I \\
\hline A set of Paediatric laryngoscope & 2 & 1 & 1 & 12 & I & 1 & 7 & I & I \\
\hline A set of Paediatric endotracheal tube & 2 & 1 & 1 & 6 & 2 & 2 & 5 & 2 & 2 \\
\hline Adult laryngoscope set & 2 & I & 1 & 8 & I & 1 & 6 & I & I \\
\hline Hydraulic trolleys & & & & 5 & I & 1 & 5 & I & I \\
\hline Adult weighing Machine & & & & 7 & 2 & 2 & 7 & 2 & 2 \\
\hline Sphygmomanometer & 6 & 4 & 3 & 13 & 6 & 4 & 12 & 6 & 4 \\
\hline Bi-aural Stethoscope & 2 & 2 & 2 & 8 & 4 & 4 & 7 & 4 & 4 \\
\hline Glucometer & & & & 5 & I & I & 5 & I & I \\
\hline Reagent Kit for Urinalysis & & & & 4 & I & I & 4 & I & I \\
\hline Oxygen Converter & 1 & 1 & 1 & 7 & 2 & 2 & 5 & 2 & 2 \\
\hline Delivery Couch & 6 & 4 & 4 & 5 & 3 & 2 & 5 & 3 & 3 \\
\hline Electric Suctioning Machine & 5 & 5 & 3 & 8 & I & 1 & 7 & 2 & 2 \\
\hline Mechanical Suctioning Machine & 4 & 1 & 0 & 7 & I & I & 6 & I & I \\
\hline
\end{tabular}

NR- Number Required

NoG- Number on Ground

Nf- Number Functioning 


\section{Discussion}

The effectiveness of any health facility in the provision of EmOC services depends, to a great extent, on the availability, adequacy and functionality of relevant medical equipment and related technical facilities, in addition to skilled healthcare professionals. As it is globally recognized, $5-15 \%$ of all pregnant women would develop emergencies in pregnancy and/or childbirth, such that adequate EmOC would be needed to avert death or severe consequences for the mother and the child (WHO, 2009). Our study considered the issue of maternal health services, specifically focusing on the technical dimensions of service delivery a fairly neglected issue in maternal health research. Both the opinion of health workers and our objective assessment using a purposely designed checklist indicate that secondary and tertiary health care facilities, although statutorily expected to provide comprehensive EmOC, lack adequate equipment for quality services in that regard.

Ten years prior to the current study, a national study had examined the degree to which facilities in Nigeria met the criteria for basic and comprehensive essential obstetric care (Fatusi and ljadunola, 2003). The study, which covered 12 of Nigeria's 36 states, found that a high proportion of health facilities lack essential equipment for essential obstetric care, overall, only $4.2 \%$ of public secondary and tertiary health facilities met the criteria EmOC. In another study in a Local government area in Osun State, Nigeria, ljadunola and colleagues (ljadunola, et al., 2007) showed that essential obstetric care services are generally lacking as many relevant equipment and personnel were not available in the existing health facilities. The conclusion from the current study broadly agrees with the findings of these two previous studies, and strongly suggests that Nigeria had made only slow progress over the last 10 years in term of the technical adequacy of its health facilities. Clearly, the promises and intentions of the country's reproductive health policy regarding technical facilities and agenda are yet to be realized and this is probably a major contributor to the country's poor maternal health statistics.

Several factors may have contributed to the current state of inadequacy of technical equipment for maternal health services in Nigeria. These may likely include inadequate fund allocation to the health sector, poor maintenance culture; that may result in easy damage of equipment (which are then not readily replaced), and overall poor management approach within the health sector and health facilities with the result that critical issues like equipment are not given the desired attention. Lack of accreditation systems for facilities and absence of institutionalized quality improvement mechanisms, and inadequate monitoring and evaluation of the state of health facilities and their performance are all factors that may also have been contributory. Political factors may also be a major contributor to the inadequacy of equipment within the health facilities. For examples, politicians and government officials may show more interest in using the number of new facilities established as campaign or performance issue with low attention to adequately equipping such facilities, and very little interest shown in the optimal functioning of the facilities. Political factors may also lead to situations where decision about building, equipping and operating health facilities are made without adequate involvement of relevant health experts, including the physicians and biomedical engineers.

While we believe that the result of this study likely reflects the state of technical adequacy of other public-sector health facilities for EmOC services in Osun State, it is not likely to be representative of private sector facilities in Nigeria generally, particularly as secondary health facilities are under the purview of the state governments, and state governors and the apparatus of government differ widely in terms of the attention and priority accorded to the health sector.

\section{Conclusion}

This study shows that the technical facilities for the provision of comprehensive $\mathrm{EmOC}$ are inadequate in public-sector secondary and tertiary health care facilities in Osun State, with negative consequences for the quality and impact of maternal health services. The current situation calls for a greater focus on technical capacity for the delivery of maternal health services in Nigeria in terms of availability and functioning of relevant equipment as this is critical to high-quality and impactful services that can reduce the country's high maternal mortality and morbidity burdens. A system of hospital accreditation and institutionalization of other mechanisms for quality assurance and quality improvement, including regular monitoring of the capacities and performance of health facilities will be important to address the challenge, alongside improved funding of the health sector and management of health facilities. .

\section{References}

Fatusi A.O. and ljadunola K.T. (2003)" National Study on Essential Obstetric Care Facilities in Nigeria" Federal Ministry of Health, Nigeria-Technical Report. ISBN 978-062-225-X

Federal Ministry of Health (FMOH) (2005) "Revised National Policy on Health" Abuja, Nigeria 
Federal Ministry of Health (FMOH) (2009) "The National Strategic Plan Framework (2009-2015) $\mathrm{NCH}$ Adopted 2009”. Abuja, Nigeria

Federal Ministry of Health (FMOH) (20I0) "National Reproductive Health Policy"

Abuja, Nigeria

Federal Ministry of Health (FMOH) (200I) "National reproductive health policy and strategy to achieve quality reproductive and sexual health for all Nigerians" ISBN:978-062-838-X

ljadunola K.T, Fatusi A.O., Orji E.O., Adeyemi A.B., Owolabi O.O., Ojofeitimi E.O., Omideyi K.O. and Adewuyi A.A. (2007) "Unavailability of Essential Obstetric Care Services in a Local Government Area of South-West Nigeria" The Journal of Health, Population and Nutrition. ISSN: 16060997 EISSN: 2072-I 315 Vol. 25 No I Pg 94- 100.

Nove A. (20II) "Midwifery in Nigeria: In-depth country analysis" Background document prepared for the State of the World's Midwifery Report.

Osun State Ministry of Health (OSMH) (2009) "Osun State Health Facilities Inventory" Produced by Health Planning, Research and Statistics Department, Ministry of Health, Osogbo.

Pardeshi G.S. (2005) "Medical equipment in government health facilities: Missed opportunities" Indian J Med Sci (serial online) (cited 201I Oct 27); 59:1-9. Available from: http//www.indianjmedsci.org/text.asp?2005/59/l/ $13 / 13813$

Prevention of Maternal Mortality (PMM) Network (1995) "Situation analysis of Emergency Obstetric Care: Examples from Eleven Operations Research projects in West Africa. Social Science and Medicine 40 (5) 657-667
World Health Organization (2009). "Monitoring emergency obstetric care: a handbook"

WHO, UNCEF and UNFPA (20I0) "Reproductive health at a glance: Nigeria. UN Estimates http://siteresources.worldbank.org/INTPRH/Reso urces/376374-

|3037363287|9/Nigeria422| | web.pdf (accessed November 23,20II)

World Health Organization (20I3). "A Framework for estimating the benefits of investing in maternal, newborn and child health

Zafarullah, G. (2000) "Implementing Emergency Obstetric Care in developing countries" Draft unpublished, AMDD Project, Columbia University, New York

\section{Authors' contributions}

A.S.S. Conceived the idea, involved in writing of the introduction, literature review, data collection, data analysis and writing of results and discussions

F.A.O. Worked on data analysis, writing of result and discussion as well as and contributed to other sections of the manuscript

I.M.O. Involved in the design of questionnaire, methodology, result writing and contributed to other sections of the manuscript

O.K. Wrote a part of the literature reviews and contributed to overall presentation of other sections of the manuscript.

The contents of the manuscript have never been previously published nor submitted for publication in any other journal. 